\title{
RAZÓN E INTELECTO EN BOECIO
}

\author{
Miguel Lluch-Baixauli \\ Universidad de Navarra
}

Boecio fue un maestro, para toda la Edad Media, en el empleo audaz de la razón. Quizás se podría encontrar el índice más revelador del «racionalismo» boeciano en la famosa regla en la que denuncia, entre las condiciones del asentimiento intelectual, la posible debilidad del argumento de autoridad: «locus ab auctoritate est infirmissimus». ${ }^{1} O$ también, en un contexto teológico, su célebre sentencia: «fidem, si poteris, rationemque coniunge». ${ }^{2}$

Como es bien sabido, Boecio es el creador de muchos vocablos que pasaron a la terminología de la tradición latina con la traducción que él les dió. Entre ellos los más importantes son los términos que acuñó impulsado por su propia reflexión personal, entre los que destacan los conceptos de persona y naturaleza. También este es el caso del famoso par: «intellectibile»-«intelligibile» 0 «intellectus»-«intellegentia». ${ }^{3}$ Boecio comprendía, apropiándose de la intuición griega y haciéndola latina, la complejidad de la realidad, que no se deja agotar en un único plano epistemológico, y que exige a la capacidad humana de conocer que se adapte en lo posible a esa pluralidad de la cognoscibilidad de lo real.

Como señaló Marie-Dominique Chenu, con estos términos Boecio reforzó el dualismo platónico, tanto epistemológico como metafísico. Ala vez, concretizó el vocabulario agustiniano, que aunque había dado ya continuidad al dualismo platónico, era cambiante en su expresión terminológica. ${ }^{4}$

1 Boecio, In topica Ciceronis commentaria, 6; De differentiis topicis, 3 (PL 64, 1166 C, 1174).

2 Boecio, Utrum Pater et Filius et Spiritus Sanctus de divinitate substantialiter praedicentur (PL 64, 1302 C).

3 Boecio, In Porphyrium dialogi a Victorino translati, I (PL 64, 11 B-C): «Noeta, inquam, quoniam latino sermone nunquam dictum repperi, intellectibilia quod unum atque idem per se in propria semper divinitate consistens, nullis umquam sensibus sed sola tantum mente intellectuque capitur quae res ad speculationem Dei atque ad animi in corporalitatem considerationemque verae philosophiae indagatione componitur; quam partem Graeci theologiam nominant. Secunda vero est pars intelligibilis, quae primam intellectibilem cogitatione atque intelligentia comprehendit».

4 Cf. Marie-Dominique Chenu, La théologie au douzième siècle, Vrin, Paris, 1957, pp. 155-156; JosepIgnasi Saranyana ha apuntado que de la obra boeciana se desprende una teoría del conocimiento propia (cf. Historia de la Filosofía Medieval, Eunsa, Pamplona, 1989, p. 83). 
Esta distinción boeciana penetró hondamente en el pensamiento medieval, sobre todo en los escritos de los psicólogos espirituales. Y los numerosos tratados escolásticos De anima recogieron también estas categorías, bajo vocabularios diversos. ${ }^{5}$

Para exponer lo que Boecio entendía por «ratio» y por «intellectus» comenzamos por la . cuestión de la clasificación de las ciencias. Fue Albino quien señaló tres grandes dominios al saber científico: ${ }^{6} 1^{\circ}$ la lógica, con una función propedeútica a toda ciencia. $2^{\circ}$ la ética, dividida a su vez en política y económica. $2^{2}$ la física, que estudia los géneros o formas del ser. A continuación Albino distinguió tres grados de ciencia: $1^{\circ}$ la física propiamente dicha, que estudia el mundo visible (celeste y sublunar). $2^{\circ}$ la matemática. $3^{\circ}$ la teología, que estudia el mundo de lo divino y de los principios del ser. Esta clasificación de Albino se mantuvo, con sólo diferencias de matiz, en Jámblico, Plotino, Alejandro de Afrodisia, el Pseudo-Alejandro, Ammonio de Ermia y David el Armenio. ${ }^{7}$

Boecio recogió toda esta larga tradición, dándole una nueva interpretación. En la obra boeciana hay dos clasificaciones de las ciencias. La primera se encuentra en su Comentario al Isagoge de Porfirio. La segunda, en su opúsculo teológico Quomodo Trinitas unus Deus ac non tres dii. ${ }^{8}$

En el comentario a la obra porfiriana, comenzó por hablar de la filosofía como amor y búsqueda de la sabiduría. Esta definición que no abandonará ya la tradición occidental, era para Boecio no sólo el amor de la sabiduría que viene de las artes humanas, sino también de la que viene de Dios y a El reconduce. A continuación, Boecio dividió la filosofía en dos niveles: práctica (activa) y teorética (especulativa). Y dentro de la filosofía especulativa distinguió a su vez tres grados distintos de seres: $1^{\circ}$ los «intellectibilia» (Dios y el alma separada del cuerpo). $2^{2}$ los «intellegibilia» (los cuerpos celestes en su eterno movimiento, los principios activos del mundo sublunar y el alma humana unida al cuerpo). $3^{\circ}$ los «naturalia» (los cuerpos materiales).

Como se ve, Boecio distinguió aquí los grados del conocimiento filosófico atendiendo a los distintos grados del ser, puesto que para él el ser es el objeto del verdadero conocimiento.

5 Ricardo de San Victor apoyó en la distinción boeciana su análisis de los grados de la contemplación. La inteligencia tiene un valor religioso, sólo ella prueba a Dios (Cf. Benjamin maior, I, 7 [PL 196, 72]). Para Thierry de Chartres la inteligencia es la facultad propiamente teológica, mientras que el entendimiento («ratio») es la facultad del ser predicamental y cuantificable. Y Hugo de San Victor encontró, gracias a la distinción boeciana, el lugar propio de la teología en su clasificación de las ciencias (cf. Didascalion, II, 2).

6 Vivió en Esmirna en el siglo II. Fue discípulo de Gayo y maestro de Galeno. Perteneció a la corriente medio platónica que intentó fundamentar eclécticamente el pensamiento platónico con elementos estoicos y aristotélicos. Se le atribuyen un Prólogo a Platón (estracto de un escrito mayor) y el Epitome o Didascalion (una introducción a la filosofía platónica). Cf. R. E. Witt, Albinus and the History of Middle Platonism, Cambridge, 1973, en especial pp. 104-144; P. Louis, Albinus. Epitome, Paris, 1945. Traducción francesa del tratado de Albino, acompañada de la versión griega. Véanse especialmente los capítulos 7 al 26.

7 Cf. P. Merlan, From Platonism to Neoplatonism, Aia, 1953, en especial pp. 5-377; J. Marietan, Le problem de la classification des sciences d'Aristote à Saint Thomas, St. Maurice, Valois, 1901; I. A. Weisheipl, Classification of the sciences in the Medieval Thought, en «Medieval Studies» 27 (1965) 54-90.

8 Boecio, In Porphyrium dialogi a Victorino translati, I (PL 64, 10-11); Quomodo Trinitas unus Deus ac non tres dii, II (PL 64, $1250 \mathrm{~A}-\mathrm{B})$. 
La metafísica es anterior a la epistemología. No manda el conocimiento sino la realidad.

Veamos ahora su segunda clasificación, expuesta en el opúsculo teológico sobre la Trinidad. En esta obra de madurez se ve que Boecio incluía lo anterior pero dándole una estructura más sólida, más personal. Dividió la filosofía en tres grados:

1-física, que estudia las realidades sensibles y corpóreas en su aspecto formal («naturalis»). Es decir, las realidades consideradas en movimiento y no abstraídas de la materia («in motu inabstracta»).

$2^{-}$matemática, que considera las mismas realidades sensibles, realmente unidas a la materia, pero consideradas mentalmente como separadas de ella. Es decir, la cantidad abstraída del movimiento por la mente («sine motu inabstracta»).

3o teología, que estudia las formas que trascienden la materia, inmóviles e inmutables. Es decir, las realidades abstraídas de la materia y del movimiento no por la mente, sino ontológicamente, en sí mismas («sine motu abstracta»).

En esta segunda clasificación, Boecio distinguió por los grados de conocimiento. Es decir, que en este escrito posterior, en relación con su comentario a Porfirio, nuestro autor se mostraba más interesado por la capacidad del sujeto cognoscente que por la comprensibilidad del objeto conocido. En este sentido, podemos afirmar que dió un paso especulativo en la doctrina epistemológica. Para Boecio el conocimiento depende del objeto conocido (los grados del ser), pero sobre todo depende del sujeto que conoce.

En efecto, en su última obra, la Consolación de la Filosofía, desarrolló este aspecto subjetivo del conocimiento y afirmó: «Si, como hemos demostrado anteriormente, el conocimiento de las cosas no depende de la naturaleza de ellas sino de la del ser que las conoce, examinemos...».9

Continuando con la clasificación del opúsculo trinitario. Boecio señaló el método que corresponde a cada uno de los tres grados de la filosofía especulativa, y lo hizo atendiendo al tipo de actividad mental que estos requieren por parte del hombre. Así, pues, afirmó lo siguiente: «In naturalibus igitur rationaliter, in mathematicis disciplinaliter, in divinis intellectualiter versari oportebit». ${ }^{10}$ No es fácil interpretar estos tres modos de actividad mental, y este es el punto central de nuestra investigación: ¿qué significaban para Boecio los términos «rationaliter» e «intellectualiter»? Más en concreto, ¿en qué se diferencian, según Boecio, la actividad propia de la «ratio» de la del «intellectus»?

Para encontrar la respuesta recurrimos otra vez a su última obra. En la Consolatio Philosophiae presentó la siguiente clasificación de las facultades cognoscitivas:

$1^{\circ}$ «sensus», que es lo propio de los animales ínfimos.

$2^{\circ}$ «imaginatio», que poseen los animales superiores, los que se mueven.

30 «ratio», que es el conocimiento del ser humano.

$4^{2}$ «intellegentia», que es el propio de Dios.

9 Boecio, Consolatio Philosophiae, 5, prosa 6, 1 («Corpus Christianorum» 94, p. 12): «omne quod scitur non ex sua sed ex comprehendentium natura cognoscitur».

10 Boecio, Utrum Pater et Filius et Spiritus Sanctus unus Deus ac non tres dii, II (PL 64, 1250 B). 
Cada una de estas facultades incluye también el acceso a los objetos propios de las facultades inferiores. Pero si la «inteligencia» es sólo propia de Dios, esta clasificación parece negar el dualismo noético al que nos estamos refiriendo, puesto que limita al hombre a la «ratio» y nada más. Más adelante, en este mismo sentido, afirmó: «ratio vero humani tantum generis est sicut intellegentia sola divini»."11

Ahora bien, esto sólo lo hizo en el contexto de la Consolación que acabo de citar. Pero aquí Boecio distinguía «ratio» de «intellegentia» para señalar los límites de la capacidad del conocimiento humano respecto al conocimiento divino. En efecto, en el mismo contexto, para subrayar la diferencia que existe entre la eternidad divina y la duración humana, Boecio afirmó que el intelecto humano es creado, mientras que la inteligencia divina es increada: «Así como dista lo que es creado y engendrado de aquello que subsiste en sí y por sí, el tiempo y la eternidad, así dista la «ratiocinatio» humana del «intellectus» divino». ${ }^{12}$ De esta forma lograba distinguir radicalmente entre el hombre y Dios, afirmando un salto infinito.

Pero en otros contextos, nuestro autor no dejó de hablar de «intellectus» humano o de «ratio» divina. Y, al mismo tiempo, reconoció en el hombre dos potencias distintas que calificó de «intellectus» $y$ «ratio». En efecto, en otros lugares Boecio atribuye al hombre el «intellectus» y que lo coloca por encima de la «ratio» humana. Con la razón percibimos, con el intelecto discernimos. En otros lugares atribuye a Dios la «ratio». ${ }^{13}$

Es con estas dos facultades con las que el hombre tiene la capacidad de conocer «rationaliter»e «intellectualiter»y, por consiguiente, según Boecio, la capacidad de pensar no sólo matemática sino también teológicamente. ${ }^{14}$ En general Boecio empleó el término «ratio» en el sentido del «logos» griego. Es decir, en el sentido lógico-epistemológico de método, discurso definitorio o argumentativo, facultad de la argumentación o de la demostración. ${ }^{15}$

Al tratar del objeto y del procedimiento de la «ratio» humana Boecio manifestó su filiación aristotélica. En efecto, para Boecio el conocimiento humano parte de los datos de los sentidos

11 Boecio, Consolatio Philosophiae, 5, prosa 5, $2-4$ («CChr» 94, p. 100). Platón había afirmado: «De la inteligencia participan los dioses y sólo una pequeña parte de los hombres» (Timeo, 51 e). Según la frase de Platón la mayoría de los hombres quedan al nivel de la opinión pero algunos acceden a la inteligencia, mientras que
Boecio restringe la inteligencia a Dios.

12 Cf. Boecio, Consolatio Philosophiae, IV, prosa 6, 17 («CChr» 94, p. 81).

13 Véase por ejemplo, In librum de interpretatione (PL 64, 297 B): «res sunt quas animi ratione percipimus, intellectuque discernimus». Obsérvese que no sólo atribuye el «intellectus» al hombre, sino que lo coloca por encima de la «ratio». Véase también, para la «ratio divina»: Consolatio Philosophiae, 3, 9: «O qui perpetua mundum ratione gubernas»; y también 4, prosa 6, 9 («CChr»94, p. 80). Sin embargo, la palabra «intellegentia» la reservó siempre a Dios.

14 Cf. la monografía de Bruno Maioli, Teoria dell' essere e dell' esistente e classificazione delle scienze in M.S. Boezio. Una delucidazione, Bulzoni Editore, Roma, 1978. El autor concluye afirmando que Boecio negó la posibilidad de la ciencia teológica. Según la interpretación de Maioli, de la que discrepo, puesto que el «intellectualiter» sería sólo propio de Dios, el hombre no podría alcanzar una ciencia de lo divino y quedaría reducido a una especulación «rationaliter». Para Maioli, no se puede hablar de ciencia teológica hasta Gilberto
de la Porrée y Pedro Abelardo.

15 Boecio, De differentiis topicis, I (PL 64, 1174 C): «argumentum est ratio rei dubiae faciens fidem»; De interpretatione, I, 1, 5 (Ed. Meiser, p. 72): «De ratione, idest de definitione quam Graeci logon dicunt». 
y de la imaginación. Hasta aquí llegaría la potencia del «sensus» y la «imaginatio». A continuación, y con capacidad autónoma, la «ratio» accede a las formas (las naturalezas, las esencias de las cosas), y las abstrae formando el universal. De esta manera la «ratio» realiza el procedimiento de la «compositio» y de la «divisio». Es decir, define conceptualmente la naturaleza de las cosas que ha captado por los sentidos, y juzga, sintetizando, según esa definición a partir de lo sensible. Así, pues, Boecio apuntó la solución al problema de los universales con su explicación del conocimiento abstractivo de raíz aristotélica. ${ }^{16}$

Es ahora, una vez abstraídas las formas, cuando entra en acción el «intellectus» boeciano y precisamente, para señalar los límites de la «ratio». En efecto, la «ratio» sólo conoce lo que es sensible e imaginable («et quod sensibile est et quod imaginabile»). ${ }^{17} \mathrm{Es}$ decir, abstrayendo de lo sensible. Pero en el hombre hay más que «ratio», y así es como Boecio lograría superar el empirismo cerrado aristotélico. La «ratio» necesita un correctivo, no agota toda la realidad.

Ahora, al dar el paso al «intellectus», Boecio recogió la clásica tesis platónica de los dos mundos (inteligible y sensible). Mientras que para explicar la abstracción del sensible siguió a Aristóteles; para el conocimiento de la realidad que escapa a los sentidos se apoyó en Platón y así hay que entender el «in divinis intellectualiter».

En efecto, para elevarse al saber teológico hay que dar un salto teorético («intellectualiter»), que consiste, según la descripción boeciana, en trascender todo dato sensorial («nullis umquam sensibus») porque los sentidos no llegan a captar los objetos trascendentes. Y no dejarse engañar por la imaginación («nulla imaginatione diduci»), que sólo serviría para la física («rationaliter»). El método o grado de especulación intelectual significa para Boecio dejar atrás el mismo proceso de la abstracción. Y esto porque Dios es forma ontológicamente pura y trascendente más allá de todo dato sensorial.

En definitiva, la «ratio» depende completamente de los sentidos. Percibe la realidad sin acabar de entenderla, su acceso a la realidad es siempre parcial y analítico. El «intellectus», por encima de las imágenes sensibles, aunque necesitado de ellas como condición previa, discierne, entiende y llega a la síntesis. Precisamente por eso, la potencia del «intellectus» se asemeja más a la «intellegentia» divina, porque se acerca más a la totalidad. Y quizás así se explican las variantes terminológicas boecianas cuando trata la inteligencia humana y la divina de las que hemos hablado antes.

«Intellectus» $\mathrm{y}$ «ratio»-no son dos facultades distintas, sino dos momentos dentro de la única capacidad humana de conocer: «animi ratione percipimus intellectuque discernimus». ${ }^{18}$

16. Para su explicación del problema de los universales cf. In Porphyrium dialogi a se translati (PL 64, 84 D-86 A); también las referencias a esta cuestión en Utrum Pater et Filius et Spiritus Sanctus unus Deus ac non tres dii, II, 5 (PL 64, 1250); Quomodo substantiae in eo quod sint bonae sint cum non sint substantialia bona (PL 64, 1311-1314); Contra Eutychen et Nestorium, III (PL 64, 1343 C-1345 B); Consolatio Philosophiae, 5, prosa 5 («CChr» 94, pp. 100-101). Como apuntó Fernand Van Steenberghen: «en el pensamiento boeciano, la doctrina del conocimiento y la lógica son aristotélicos. El fue sin duda un precursor del realismo moderado» (cf. Histoire de la Philosophie. Pèriode chrétienne, Louvain-Paris, 1973, p. 44).

17 Para la explicación del proceso cf. Boecio, Consolatio Philosophiae, 5 («CChr» 94, pp. 89-106).

18 Boecio, In librum de interpretatione (PL 64, $297 \mathrm{~B}$ ). 
El hombre es capaz de pensar «rationaliter» e «intellectualiter» y, precisamente por ello puede acceder al conocimiento de Dios. Esta distinción en dos momentos de la inteligencia humana bien podría ser un precedente de la doctrina del conocimiento tomasiana. ${ }^{19}$

Con frecuencia afirmó Boecio no sólo que el conocimiento de Dios es posible al hombre, sino que le es infinitamente valioso. $Y$ en sus escritos puede encontrarse una auténtica síntesis teológica. ${ }^{20}$ Ahora bien, este «momento intelectual» que es complementario y superior al racional, y que permite al hombre teologizar, tiene también sus límites.

Para terminar, presento una explicación sintética de cómo entendía Boecio los límites y las posibilidades del «intellectus» humano. En su opúsculo teológico Contra Eutychen et Nestorium, para dar una definición de «naturaleza» afirmó: «Naturaleza es todo aquello que, en cuanto que es, de algún modo puede ser comprendido por el intelecto». ${ }^{21}$ Es dificil encontrar una definición que contenga mayor optimismo gnoseológico que ésta. La realidad («natura») es definida por la posibilidad de ser captada por el intelecto humano. ¿Qué es la realidad?, lo que puede ser conocido. Ahora bien ¿dónde está el límite? Y a continuación Boecio aclara: «Hemos dicho de algún modo porque Dios y la materia no pueden ser entendidas por el intelecto de modo íntegro y perfecto».22

Este es el límite del «racionalismo» boeciano. Hay una parte de la realidad, su naturaleza más profunda, que no puede ser agotada por el intelecto («intellectus») humano. Y es aquí, finalmente, donde se puede encontrar la posibilidad del «in divinis intellectualiter». Precisamente cuando se afirma su límite. Si Boecio afirma que el «intellectus» humano no puede captar de modo íntegro y perfecto el ser divino, es porque sí puede captar algo de ese ser, y en esa medida, la ciencia teológica es posible.

19 Sobre la cuestión cf. P. Rousselot, L'intellectualisme de saint Thomas, Paris, 1924; A. Dondeyne, Foi chrétienne et pensée contemporaine, Louvain 1951, especialmente el cap. III: L'irrationel et la raison dans la pensée contemporaine, pp. 53-103. Y la reciente aportación a esta cuestión de Colm McClements, The distinction intellectus-ratio in the Philosophy of Thomas Aquinas. A historical and critical study, Tesis doctoral dirigida por el Prof. James McEvoy, Institut Supérieur de Philosophie, Université Catholique de Louvain, Louvain-la-Neuve, 1990 , inédita.

20 Cf. Claudio Micaelli, Studi su $i$ trattati teologici di Boezio, M. D’Auria («Col. Speculum»), Napoli, 1988; Miguel Lluch-Baixauli, La teología de Boecio, Eunsa («Colección Teológica» 69), Pamplona, 1990.

21 Boecio, Contra Eutychen et Nestorium (PL 64, 1341 B): «Natura est earum rerum quae, cum sint, quoquomodo intellectu capi possent».

22 Boecio, Contra Eutychen et Nestorium (PL 64, 1341 B): «aditum vero quoquomodo, quoniam Deus et materia integro perfectoque intellectu intellegi non possunt». 